\title{
A systemic failure to address at-risk drinking and alcohol use disorders: the Canadian story
}

\author{
Sheryl Spithoff MD, Suzanne Turner MD MBS
}

CMAJ Podcasts: author interview at soundcloud.com/cmajpodcasts/spithoff-drinking

See also page 502 and www.cmaj.ca/lookup/doi/10.1503/cmaj.140254

A lcohol use disorders, defined as clinically significant impairment or distress from the use of alcohol, are common in Canadian society. ${ }^{1}$ In addition, $15 \%$ to $20 \%$ of Canadians who do not meet the criteria for an alcohol use disorder drink more than what is recommended by the low-risk guidelines. ${ }^{2}$ Alcohol-related harms attributable to both at-risk drinking and alcohol use disorders are responsible for $9.3 \%$ of disability-adjusted life-years lost and $7.1 \%$ of all premature deaths in Canada. ${ }^{3}$ The costs to the health care system are high.

As Moyer and Finney ${ }^{4}$ outline in their clinical review, patients with at-risk drinking and alcohol use disorders can be easily identified with validated screening procedures. Conversely, when physicians rely on case identification alone, patients with at-risk drinking and milder alcohol use disorders (who typically have stable lives and few consequences from drinking) are often missed. These patients, however, are at high risk of harm and of progression to more severe disease, so effective interventions are important. Evidence has shown that they respond well to brief interventions. Moyer and Finney ${ }^{4}$ review the robust evidence for such interventions and describe how they can be delivered. Indeed, Canada's national alcohol strategy calls for widespread implementation of systematic screening and brief intervention programs in health care settings. ${ }^{5}$

Patients with more severe alcohol use disorders also respond to medical interventions, provided such interventions are more intensive. ${ }^{6}$ These patients are often interested in treatment: increased severity of an alcohol use disorder is associated with increased perception of problems, which in turn is a predictor of treatment readiness. ${ }^{7}$ Therefore, most experts recommend that providers refer these patients to specialized addiction care. However, specialized clinics have high no-show rates and low retention in treat- ment, ${ }^{8}$ and real-world success rates are likely lower than those achieved in research trials.

A newer treatment model may address the high no-show rates in specialized clinics through provision of addiction care at each patient's own primary care clinic. In this model, primary care providers without specialized addiction training or counselling skills deliver multiple brief counselling sessions, appropriate pharmacotherapy and connections to other addiction resources. The COMBINE study ${ }^{9}$ was designed to compare this primary care management model with specialized addiction care. The researchers randomly assigned 1383 patients to nine treatment groups and found that none of the treatment groups outperformed the primary care medical management model. As well, a systematic review of treatment of alcohol use disorders ${ }^{6}$ found similar positive outcomes with primary care medical management models and specialized addiction care models.

Medications are an important component of care for those with more severe alcohol use disorders, in both specialized and primary care settings. ${ }^{6}$ The first-line medications are naltrexone and acamprosate. A recent meta-analysis ${ }^{10}$
Competing interests: None declared.

This article has been peer reviewed.

Correspondence to: Sheryl Spithoff, sheryl.spithoff@wchospital.ca

CMAJ 2015. DOI:10.1503 /cmaj.140849 
determined that the number needed to treat was 12 for both naltrexone to prevent heavy drinking and acamprosate to achieve abstinence. Medications are also cost-effective, reducing total health care costs by $30 \%$ in one analysis. ${ }^{11}$

Despite evidence of benefit, Canadians with atrisk drinking and alcohol use disorders rarely receive any of these effective interventions. Screening and brief intervention programs have not been widely implemented. ${ }^{12}$ In an analysis of six primary care clinics in Manitoba, physicians had documented patients' alcohol use in only $23 \%$ of patient charts. ${ }^{13}$ Additionally, it appears that very few of those with diagnosis of an alcohol use disorder are using first-line medications. For example, between April 2011 and March 2013 , only 36 of the 16212 Ontarians on public drug benefits who had an alcohol use disorder filled a prescription for a first-line medication in the year after their diagnosis (Spithoff S, Turner S, Gomes T, et al. 2014. Unpublished data from Ontario Drug Policy Research Network project, Institute for Clinical Evaluative Sciences). Ontario does not include these medications on the general formulary for public drug beneficiaries, so rates of use may be different for patients with private drug coverage.

Failures throughout our health care system underpin this travesty. Medical schools and residency programs provide little addiction education. ${ }^{14}$ In the 2010 Canadian National Physician Survey, only $48 \%$ of family medicine residents reported that training in substance use was available. ${ }^{15}$ Few hospitals have an addiction medicine service. ${ }^{12}$ As a result, hospitals often focus on treating the consequences of alcohol problems, not the condition itself. Most provincial and territorial payers give minimal support for hospitals and primary care providers to care for those with at-risk drinking and alcohol use disorders. Additionally, like Ontario, most provinces and territories do not include first-line medications on their general formularies: either they do not fund the medications at all or they permit access only through a special request process.

The following policy changes would help to ensure equitable care for those with at-risk drinking and alcohol use disorders, thereby reducing the burden of disease and saving costs. First, medical schools, residency programs and licensing bodies should ensure that their educational standards reflect the burden of disease from these conditions. Additionally, they should require that graduates who will work in primary care settings (clinics and emergency departments) be proficient in the screening, identification and management of at-risk drinking and alcohol use disorders, not just the management of the health consequences. Second, provinces and territories should provide support for the primary care management of alcohol use disorders by funding billing codes that reflect the complexity of care. Third, hospitals and primary care clinics should implement systematic screening and brief intervention programs and create pathways to connect those patients with more severe alcohol use disorders to ongoing addiction care. Finally, all provinces and territories should include the first-line medications for alcohol use disorders - naltrexone and acamprosate - on their general public formularies.

\section{References}

1. Mental and substance use disorders in Canada. Ottawa: Statistics Canada; 2013. Cat. no. 82-624-X. Available: www.statcan .gc.ca/pub/82-624-x/2013001/article/11855-eng.htm (accessed 2015 Jan. 15).

2. Canadian alcohol and drug use monitoring survey: summary of results for 2011. Ottawa: Health Canada; 2012. Available: www .hc-sc.gc.ca/hc-ps/drugs-drogues/stat/_2011/summary-sommaire -eng.php\#a7 (accessed 2014 Dec. 10).

3. Shield KD, Kehoe T, Taylor B, et al. Alcohol-attributable burden of disease and injury in Canada, 2004. Int J Public Health 2012;57:391-401.

4. Moyer A, Finney JW. Brief interventions for alcohol misuse. CMAJ 2015;187:502-6.

5. National Alcohol Strategy Working Group. Reducing alcoholrelated harm in Canada: toward a culture of moderation. Recommendations for a national alcohol strategy. Edmonton and Ottawa: Alberta Alcohol and Drug Abuse Commission, Canadian Centre on Substance Abuse and Health Canada; 2007. Available: www.aglc.ca/pdf/social_responsibility/nationalalco holstrategy.pdf (accessed 2015 Feb. 18).

6. Miller PM, Book SW, Stewart SH. Medical treatment of alcohol dependence: a systematic review. Int J Psychiatry Med 2011;42:227-66.

7. Bertholet N. Factor structure of the SOCRATES questionnaire in hospitalized medical patients. Addict Behav 2009;34:568-72.

8. Molfenter T. Reducing appointment no-shows: going from theory to practice. Subst Use Misuse 2013;48:743-9.

9. Anton RF, O'Malley SS, Ciraulo DA, et al. Combined pharmacotherapies and behavioral interventions for alcohol dependence: the COMBINE study: a randomized controlled trial. JAMA 2006;295:2003-17.

10. Jonas DE, Amick HR, Feltner C, et al. Pharmacotherapy for adults with alcohol use disorders in outpatient settings: a systematic review and meta-analysis. JAMA 2014;311:1889-900.

11. Baser O, Chalk M, Rawson R, et al. Alcohol dependence treatments: comprehensive healthcare costs, utilization outcomes, and pharmacotherapy persistence. Am J Manag Care 2011; 17(Suppl 8):S222-34.

12. El-Guebaly N. A Canadian perspective on addiction treatment Subst Abus 2014;35:298-303.

13. Singer A, Yakubovich S. Data quality in the WRHA: Is our data reliable? [PowerPoint presentation]. Winnipeg: Winnipeg Regional Health Authority; 2013. Available: www.manitoba -ehealth.ca/conference/files/conf2013BR1.ppt (accessed 2015 Feb. 6).

14. El-Guebaly N, Crockford D, Cirone S, et al. Addiction medicine in Canada: challenges and prospects. Subst Abus 2011;32:93-100.

15. Canadian National Physician Survey, 2010. Results for family medicine residents. Missisauga (ON): National Physician Survey; 2010. Available: http://nationalphysiciansurvey.ca/wp-content /uploads/2012/09/2010-ResFM-Q11.pdf (accessed 2015 Feb. 12).

Affiliations: Family Medicine (Spithoff), Women's College Hospital, Toronto, Ont.; St. James Town Health Centre (Turner), St. Michael's Hospital, Toronto, Ont.

Contributors: Sheryl Spithoff and Suzanne Turner conceived of and designed the article. Sheryl Spithoff wrote the first draft, and Suzanne Turner revised the manuscript critically. Both gave final approval and agree to act as guarantors of the work. 